Meuwissen, L.E., Gorter, A.C., Knottnerus, A.J.A. Impact of accessible sexual and reproductive health care on poor and underserved adolescents in Managua, Nicaragua: a quasi-experimental intervention study. Journal of Adolescent Health: 2006, 38(1), 56

\begin{tabular}{|l|l|}
\hline $\begin{array}{l}\text { Postprint } \\
\text { Version } \\
\text { Journal website }\end{array}$ & 1.0 \\
\hline $\begin{array}{l}\text { Pubmed link } \\
\text { http://www.jahonline.org/article/PIIS1054139X05000273/abstract }\end{array}$ & $\begin{array}{l}\text { http://www.ncbi.nlm.nih.gov/sites/entrez?Db=pubmed\&Cmd=ShowDetailView } \\
\text { \&TermToSearch=16387251 }\end{array}$ \\
\hline DOI & $\begin{array}{l}\text { 10.1016/j.jadohealth.2005.01.009 } \\
\text { This is a NIVEL certified Post Print, more info at http://www.nivel.eu }\end{array}$
\end{tabular}

\title{
Impact of accessible sexual and reproductive health care on poor and underserved adolescents in Managua, Nicaragua: a quasi-experimental intervention study
}

Liesbeth E. Meuwissen, M.D., M.SC. ${ }^{A}{ }^{*}$, AnNA C. Gorter, M.D., Ph.D. ${ }^{\mathrm{B}}$, AND ANDRÉ J.

\author{
A. KNOTTNERUS, M.D., Ph.D. ${ }^{\mathrm{C}, \mathrm{DA}}$ \\ anstituto CentroAmericano de la Salud, Managua, Nicaragua \\ ${ }^{\mathrm{b}}$ London School of Hygiene \& Tropical Medicine, London, United Kingdom \\ 'University of Maastricht, Maastricht, The Netherlands \\ ${ }^{d}$ Health Council of the Netherlands, The Hague, The Netherlands \\ Manuscript received August 31, 2004; manuscript accepted January 4, 2005
}

\begin{abstract}
Background: The objective of this study was to evaluate a competitive voucher program intended to make sexual and reproductive health care (SRHC) accessible to adolescents from disadvantaged areas of Managua.

Methods: A quasi-experimental intervention study was performed in which 28,711 vouchers that gave free access to SRHC in 20 health centers, were distributed to adolescents. To evaluate the impact, community sampling took place in markets, neighborhoods, and outside schools where self-administered questionnaires were distributed. The study comprised a random sample of 3,009 female adolescents, ages 12 to 20 years old, 904 voucher receivers and 2,105 nonreceivers. Their use of SRHC, and knowledge and use of contraceptives and condoms were measured.
\end{abstract}

Results: Voucher receivers had a significantly higher use of SRHC compared with nonreceivers, 34\% versus 19\% (adjusted odds ratio, 3.1; 95\% confidence interval, 2.5-3.8). The highest influence was seen among respondents at schools, where use was $24 \%$ relative to $6 \%$ in nonreceivers (adjusted odds ratio, 5.9; 95\% confidence interval, 3.7-9.5). Voucher receivers answered significantly more questions correctly that were related to knowledge of contraceptives and sexually transmitted infections than nonreceivers.

At schools, sexually active voucher receivers had a significantly higher use of modern contraceptives than nonreceivers, $48 \%$ versus 33\% (adjusted odds ratio, 2.3; $95 \%$ confidence interval, 1.2-4.4); and in neighborhoods, condom use 
Meuwissen, L.E., Gorter, A.C., Knottnerus, A.J.A. Impact of accessible sexual and reproductive health care on poor and underserved adolescents in Managua, Nicaragua: a quasi-experimental intervention study. Journal of Adolescent Health: 2006, 38(1), 56

during last sexual contact was significantly greater among voucher receivers than nonreceivers (adjusted odds ratio, 2.5; 95\% confidence interval, 1.4-4.5).

Conclusion: The voucher program succeeded in increasing access to SRHC for poor and underserved girls. The needs of adolescents were met with a relatively simple intervention through existing health facilities. Many adolescents appeared willing to protect themselves against the risks of sexual intercourse.

This suggest that access to SRHC can play an important role in changing youth behavior and increase the use of contraceptives and condoms. (C) 2006 Society for Adolescent Medicine. All rights reserved.

Nicaragua has the highest fertility rate in Latin America, with 119 births annually per 1,000 young women aged 15 to 19 years ${ }^{[1]}$. Girls' mean age at first intercourse is reported to be 17.8 years, but at age 15 years, $8 \%$ of the girls already are mothers or pregnant, and by age 19 this has increased to $45 \%{ }^{[1]}$. This is suggestive of the well-known underreporting of sexual activity in interview settings, and the real mean age at first intercourse may be lower than reported.

Early sexual debut and high fertility rates are associated with low socioeconomic status and educational level. Adolescents experience high rates of unwanted pregnancy, illegal abortions, and high maternal mortality, and also are at high risk for contracting sexually transmitted infections (STIs), including human immunodeficiency virus/acquired immune deficiency syndrome.

Few adolescents use family planning methods and the latency period between first intercourse and the end of first pregnancy is an average of 21.5 months ${ }^{[2]}$. Other Latin American countries face similar problems. Obstacles to accessing contraceptive services are believed to originate from different levels: adolescents and their sexual partners, health and education systems, and sociocultural factors ${ }^{[3-6]}$.

The obstacles to sexual and reproductive health services are as follows:

- Lack of access to information about sexual and reproductive health: there is no integrated sex education in schools, the media transmit ambivalent messages, and parents lack the necessary information and experience difficulties in discussing sex with their children.

- Lack of access to sexual and reproductive health care (SRHC) services: existing centers lack confidentiality, privacy, and quality of service, all factors considered essential characteristics by adolescents. Centers with specialized services for adolescents are rare and/or relatively expensive, so poor adolescents cannot access them.

- Low quality of care: many doctors lack the knowledge and skills to provide adequate SRHC consultations to adolescents and treat them in a paternalistic way.

Various interventions in the region aimed at overcoming the obstacles faced by adolescents in accessing SRHC have not resulted in an increased uptake of services and/or use of contraceptives ${ }^{[7-9]}$. This led various researchers to formulate the hypothesis that knowledge and availability of contraceptives are important but not sufficient to change adolescents' behavior. As a result, interventions are recommended that target not only adolescents and health service providers but also the social norms of parents and communities ${ }^{[7,8,10-12]}$. It is important to verify whether the formulated hypothesis is true. There is an urgent need to identify effective, low-cost interventions that assist adolescents in protecting themselves from unwanted or untimely pregnancies as well as STIs and human immunodeficiency virus. In Nicaragua, an innovative approach was piloted, focused on strengthening the demand of adolescents for SRHC through a competitive voucher scheme ${ }^{[13]}$. Competition refers to the fact that in the described program there was competition between service providers, as opposed to programs in which the voucher is redeemable at a single service provider. Competition substantially increases the potential to produce efficiency and quality improvements in the health care delivered ${ }^{[13]}$. 
Meuwissen, L.E., Gorter, A.C., Knottnerus, A.J.A. Impact of accessible sexual and reproductive health care on poor and underserved adolescents in Managua, Nicaragua: a quasi-experimental intervention study. Journal of Adolescent Health: 2006, 38(1), 56

The impact of this intervention was evaluated through self-administered questionnaires completed by female adolescents in places where vouchers had been distributed, focusing on the use of SRHC and knowledge and use of contraceptives and condoms.

\section{METHODS}

\section{The intervention}

Nicaragua is one of the poorest countries in Latin America, with an estimated population of 5.2 million inhabitants.

Managua, the capital, had an estimated population of 1 million inhabitants in 2000, of whom $25 \%$ were aged between 10 and 20 years ${ }^{[14]}$. From September 2000 to July 2001, a total of 28,771 vouchers were distributed to male and female adolescents in disadvantaged areas of Managua.

The Central American Health Institute (ICAS) was the voucher agency. Vouchers were distributed through ICAS and nongovernmental organizations (NGOs) in 4 markets, outside 19 public schools, in clinics, and on streets and house to house in 221 poor neighborhoods. Vouchers were distributed in neighborhoods because pregnancy can be a reason to be expelled from school and attendance at secondary school among female adolescents in Managua is only $73 \%{ }^{[1]}$. Less than $.5 \%$ of adolescents refused a voucher. During distribution, registers were kept recording age, gender, level of school attainment, and the socioeconomic status of each distribution site.

Vouchers were not bound to the person who originally received them and could be passed to another adolescent with greater needs (voucher traveling). Of girls who redeemed a voucher, $27 \%$ reported that they had received it from someone not directly involved in the distribution.

Vouchers were valid for 3 months and could be used for 1 consultation and 1 follow-up visit for counseling, family planning, pregnancy testing, antenatal care, STI treatment, or a combination of these services. Four public clinics, 5 private clinics, and 11 NGO clinics participated. The selection of these clinics was based on suitability and proximity to the areas where the vouchers were distributed. All voucher redeemers received a booklet on adolescent health, 2 condoms with supportive information, as well as laboratory tests, drugs, and contraceptives, as required.

Clinic staff received a short introduction to the program followed by training sessions on counseling, adolescence and sexuality, and sexual abuse. Doctors filled in a standard medical form during each consultation. Based on the numbers of completed forms with the voucher attached, the clinics received reimbursement according to agreed fees (Figure 1).

\section{[FIGURE 1]}

\section{Design and population}

The impact of this community-based quasi-experimental intervention study was assessed by comparing the use of SRHC, knowledge of contraceptives and STIs, and use of contraceptives and/or condoms from female voucher receivers compared with nonreceivers. Self-administered questionnaires were distributed randomly among female adolescents 3 to 15 months after the vouchers had been distributed in their area. The evaluation of the impact was limited to girls. To measure the impact of the intervention on male adolescents a much larger sample size would have been needed because only $6 \%$ of the male receivers used their voucher.

The sampling frame consisted of a selection of 21 of the 244 sites where a large number of vouchers had been distributed.

At each site, convenience samples of adolescent girls were asked to complete a questionnaire. The only criterion for selection was age. At markets and in neighborhoods, girls were approached individually both during voucher distribution and the survey. During 
Meuwissen, L.E., Gorter, A.C., Knottnerus, A.J.A. Impact of accessible sexual and reproductive health care on poor and underserved adolescents in Managua, Nicaragua: a quasi-experimental intervention study. Journal of Adolescent Health: 2006, 38(1), 56

voucher distribution at schools, relatively large groups of adolescents were approached while leaving their school to prevent compromising schools with the SRHC intervention. During the survey, girls were approached on a more individual basis while still in or near the school compound.

The survey was presented to girls as a study seeking adolescents' opinion on health services and was not linked to the program. The objective was to obtain a random sample of girls who had had the same chance of receiving a voucher. Within this sample, the voucher receivers were considered the intervention group to be compared at a group level with the control group, the nonreceivers, because it was by chance whether or not a respondent had received a voucher (Figure 2). The study was approved by the ethical review committees of the London School of Hygiene and Tropical Medicine and ICAS.

\section{Measurements}

A self-administered questionnaire was chosen to maximize honesty in responses given cultural taboos about premarital sex. The wording of the questions was developed in conjunction with adolescents from participating NGOs and was piloted extensively. The main challenge was to collect information on voucher receipt and use without overtly linking the questionnaire to the evaluation of the program.

While the questionnaire was being completed, survey staff (female adolescents) stayed nearby to answer questions and to safeguard privacy. Of completed questionnaires, $18 \%$ had been filled in by survey staff on behalf of girls who had difficulties reading or writing.

The aim of the study was to assess whether the voucher program, through increased access to SRHC, would increase knowledge about STIs and contraceptive methods as well as increase contraceptive use. The selection of the variables was based on literature and previous studies in Nicaragua. The main outcome variables were as follows: (1) using SRHC within 15 months before the survey; (2) mentioning at least 2 modern contraceptives; (3) mentioning a health care facility as a place to obtain contraceptives; (4) mentioning 2 STIs; (5) mentioning condoms as a method to prevent transmission of STIs; (6) reported use of modern contraceptives; and (7) reported condom use during last sexual contact.

Open-ended questions were used to assess girls' knowledge.

The use of SRHC was ascertained through the questions: "Did you consult a doctor for: information or advice, family planning methods, pregnancy test, control of pregnancy, a venereal disease, problems with your menstruation, or other?" (with a yes/no response). "How many months ago did you have this medical consultation?" With 2 exceptions, questions about sexual activity and the use of contraceptives and condoms were formulated with yes/no responses. Girls who used contraceptives were asked to fill out the name of the method and all girls were asked to provide the age at which they wanted to have their first or their next child.

\section{[FIGURE 2]}

\section{[TABLE 1]}

The main exposure was voucher receipt. The variables of age, level of schooling, school attendance, socioeconomic (SE) indicators, childbearing experience, and survey site were considered potential confounders that might have been associated with receiving a voucher and independently influence outcome, or effect modifiers that might influence the effect of vouchers on outcome.

SE indicators used to assess the level of relative poverty were the presence of a refrigerator, the number of people per bedroom, and SE classification of the survey site. The SE classification of neighborhoods was based on an updated list obtained from the municipality indicating the nature of housing, the level of services (sewerage, electricity, drinking water), and the quality of the roads. Markets were classified on the relative price levels of goods 
Meuwissen, L.E., Gorter, A.C., Knottnerus, A.J.A. Impact of accessible sexual and reproductive health care on poor and underserved adolescents in Managua, Nicaragua: a quasi-experimental intervention study. Journal of Adolescent Health: 2006, 38(1), 56

sold. Schools were classified on the level of parental financial contributions and the SE classification of the neighborhood. The very poor SE sites scored 2 points, followed by the poor sites with 1 point, with lower class/lower middle class sites with 0 points.

Pregnancy and motherhood increase the social acceptability of a girl seeking SRHC in Nicaragua. Therefore, the category of childbearing experience was classified into 3 groups. Group 1 comprised girls who had not started sexual relations. Group 2 comprised girls who had started sexual relations but had never been pregnant. Group 3 comprised pregnant girls and mothers. The distribution of childbearing experience by age was similar to the national distribution ${ }^{[1]}$.

\section{Data collection and analysis}

An estimated 3\% of girls refused to participate. The reasons provided included "in a hurry" and "no permission from my boss" (at markets), whereas others believed the questionnaire was related to a political activity. A total of 3,130 questionnaires were completed, of which 3,009 (96\%) contained sufficient data for analysis. Data were entered twice in Epi-info by 2 different data processors. STATA 7.0 (Intercooled) software was used for further analysis.

The main characteristics describing study participants according to voucher receipt were calculated and tabulated (Tables 1 and 2). The crude odds ratio between voucher receipt and outcomes was assessed. The adjusted Mantel- Haenszel odds ratios for the different levels of possible confounders were calculated. Only statistically significant results $(p<.05)$ are reported.

Multiple logistic regression analyses were used to adjust the association between voucher receipt and the outcome for group differences. The likelihood ratio test (LRT) was used to determine whether other variables individually had a significant effect on the outcome $(p<$ $.10)$. For each variable, it was assessed whether there was interaction with voucher receipt using the LRT. All categoric variables were tested for departure from the linear trend. Finally, the significance of each variable was tested with the LRT, by

\section{[TABLE 2]}

excluding them one by one from the model with all significant variables $(p<.05)$. Because the survey site (markets, neighborhoods, and schools) had considerable influence on the outcomes, multivariate analyses were performed for each site separately (Table 3). Only records with complete data for all significant variables were used in the multivariate analysis. Missing data were few and associated neither with the probability of voucher reception nor with any outcome.

\section{RESULTS}

During the intervention, there were 3,067 girls who used a voucher for a total of 3,301 first consultations: $34 \%$ for family planning (for sexually active nonpregnant girls, $57 \%$ ), $31 \%$ for treatment of reproductive tract infections and STIs, 28\% for antenatal care, $28 \%$ for counseling, $18 \%$ for pregnancy testing, and $15 \%$ for other reasons. Girls could attend for more than one reason. Based on the data collected during the voucher distribution, no relevant differences were found in the characteristics of the voucher receivers in sampled sites versus nonsampled sites. Furthermore, the characteristics of the respondents were similar to girls who had received a voucher during the intervention. As a result, it can be assumed that respondents are representative of the group who could have received a voucher. Of the 3,009 girls who completed the questionnaire, 904 had received a voucher and 2,105 had not. Voucher receivers and nonreceivers differed significantly in some main characteristics (Table 1). These differences disappeared in markets and neighborhoods after stratification by survey site (Table 2). By constructing separate models per site, the impact of vouchers on subgroups of adolescents was shown (Table 3 ). Correcting for the $18 \%$ of 
Meuwissen, L.E., Gorter, A.C., Knottnerus, A.J.A. Impact of accessible sexual and reproductive health care on poor and underserved adolescents in Managua, Nicaragua: a quasi-experimental intervention study. Journal of Adolescent Health: 2006, 38(1), 56

questionnaires that were completed by survey staff did not change any outcome in the logistic regression model.

\section{Use of SRHC}

The overall use of SRHC during the 15 months since voucher distribution began was 700 (23\%): 303 (33.5\%) voucher receivers compared with 397 (18.9\%) nonreceivers (Fig. 2).

Three groups profited most from voucher receipt. Of the girls completing questionnaires at school, $24 \%$ of the voucher receivers used SRHC compared with $6 \%$ of the girls who did not receive a voucher. Of the younger voucher receivers (age group, 12-15 y), 25\% used SRHC compared with $7 \%$ of the nonreceivers. Of the voucher receivers who had completed less than 7 years at school, $56 \%$ used SRHC compared with $26 \%$ (Figure 3).

When controlling through logistic regression for all covariables significantly correlated with the use of SRHC, voucher receipt was associated with a considerably higher use of SRHC. The strongest difference was seen in girls completing questionnaires at schools (Table 3).

\section{Knowledge and use of contraceptives}

Of all participants, 2,045 (68\%) mentioned at least 2 contraceptives: 667 (74\%) voucher receivers versus $1,378(65 \%)$ nonreceivers. In logistic regression analysis, voucher receipt was associated with a significantly greater capacity to mention at least 2 contraceptives. Per survey site, the influence of voucher receipt on knowledge of 2 types of contraception was absent in markets, but positive in neighborhoods and schools (Table 3 ).

Of all participants, $1,369(46 \%)$ mentioned a health care- related facility as a place to obtain contraceptives: 460 (51\%) voucher receivers versus 909 (43\%) nonreceivers.

The difference between voucher receivers and nonreceivers was largest among girls with less education ( $56 \%$ vs. $38 \%)$.

\section{[TABLE 2]}

\section{[FIGURE 3]}

In multiple logistic regression analyses, voucher receipt was associated with a significantly greater capacity to mention a health facility. When analyzing the relationship by survey site, vouchers had a significant impact in neighborhoods and at schools (Table 3 ).

From the 1,025 girls who indicated that they had begun sexual intercourse, $11 \%$ were pregnant and $2 \%$ said they wanted a baby within the coming year. For the use of modern contraceptives, only responses from the remaining 888 sexually active girls were considered. The difference between voucher receivers and nonreceivers was studied for the use of intrauterine device, sterilization, and oral or injectable contraceptives.

The overall use of modern contraceptives was 437 participants (50\%). No differences were noted between voucher receivers and nonreceivers. In multiple regression analyses, voucher receipt was associated with a nonsignificant higher use of modern contraceptives. The effect of the voucher was modified by the place of survey. At schools, voucher receipt was associated with a significantly greater use (Table 3).

\section{Knowledge of STIs and their prevention and the use of condoms}

Of all participants, 1,220 (41\%) could mention 2 STIs: 441 (49\%) voucher receivers versus $779(37 \%)$ nonreceivers.

Human immunodeficiency virus/acquired immune deficiency syndrome was mentioned by $74 \%$ of the girls independent of voucher receipt. Although the numbers of girls who mentioned 2 STIs increased with level of education, the difference between voucher receivers and nonreceivers was largest among girls with 0 to 6 years of education (33\% vs. $15 \%)$. 
Meuwissen, L.E., Gorter, A.C., Knottnerus, A.J.A. Impact of accessible sexual and reproductive health care on poor and underserved adolescents in Managua, Nicaragua: a quasi-experimental intervention study. Journal of Adolescent Health: 2006, 38(1), 56

In logistic regression analysis, vouchers were associated with an increased capacity to mention STIs. The level of education modified the impact of vouchers because the lower the level of education, the stronger the influence of voucher receipt on knowledge of STIs. When analyzing by distribution site, voucher receipt was associated with sig- nificantly better STI knowledge among respondents in neighborhoods and at schools (Table 3). Of all participants $1,480(49 \%)$ mentioned condom use as a method to prevent STIs, $487(54 \%)$ of the voucher receivers versus 993 (47\%) of the nonreceivers. In logistic regression analysis, voucher receipt was associated with a significantly greater knowledge of STI prevention through condom use. This difference was largest among respondents in neighborhoods (Table 3).

The use of condoms in the last sexual encounter among sexually active girls was 179 (21\%): 64 (23\%) by voucher receivers versus $115(20 \%)$ by nonreceivers. Although condom use was highest among girls attending school, the difference between voucher receivers and nonreceivers was strongest in girls with little education ( $29 \%$ vs. $14 \%)$ and girls not attending school ( $24 \%$ vs. $15 \%)$.

In multiple logistic regression analyses, vouchers were associated with a significant increase in condom use at last contact. The effect of the voucher was modified by school attendance because when analyzing all girls together, an increase in use was observed only among voucher receivers who were not attending school. When analyzing by survey site, condom use increased most among voucher receivers in neighborhoods (Table 3 ).

\section{DisCUSSION}

After adjustment for differences between groups, voucher receipt was associated with a significantly greater increase in the following: use of SRHC, knowledge of contraceptives, and knowledge of STIs and prevention through condom use. The impact of voucher receipt varied between subgroups. For respondents at markets only the use of SRHC increased. The use of contraceptives increased significantly among respondents at schools, and the increase in the use of condoms during last sexual encounter was strongest in neighborhoods.

In interpreting these findings, some methodologic comments should be considered. The main limitation of this study was the different characteristics of voucher receivers and nonreceivers among respondents at school. These differences can be explained by 2 mechanisms. The group approach during voucher distribution permitted a positive selection of girls with more unmet needs for SRHC (the sexually active and older girls) who were interested in receiving a voucher, whereas the more individual approach during the survey made such selection less likely. This process, together with voucher traveling, can explain the differences in age and sexual activity, controlled through logistic regression.

Because the questionnaire was completed anonymously, and in private, and was not overtly linked to the voucher program, nonrandom reporting bias is unlikely. The significant difference found between voucher recipients and nonrecipients in the use of contraceptives and condoms is promising because these differences were found within a relatively small sample of sexually active girls who did not want to conceive within 1 year.

In conclusion, voucher receipt can be considered the main causal factor for improved use of services, knowledge, and use of contraceptives and condoms in this population.

Considering the generalizability of the results, even adolescents from disadvantaged areas of Managua appear very diverse, benefiting differently from the voucher program. At markets, more girls were independent economically and had started adult life: through voucher receipt, these girls only increased their use of SRHC. In neighborhoods, more of the girls had left school mostly as a result of the SE situation of the family or pregnancy. These girls profited most from access to information and increased use of condoms. Girls at schools generally receive family support for further education and few are pregnant. In this group, knowledge increased and many used their voucher to obtain modern contraceptives. Because many adolescents in Nicaragua, as throughout Latin America, face obstacles accessing 
Meuwissen, L.E., Gorter, A.C., Knottnerus, A.J.A. Impact of accessible sexual and reproductive health care on poor and underserved adolescents in Managua, Nicaragua: a quasi-experimental intervention study. Journal of Adolescent Health: 2006, 38(1), 56

contraceptive information and services, a voucher program is likely to yield benefits for other groups of adolescents as well.

Twenty percent of the female voucher receivers used their voucher. This is a relatively high percentage considering the fact that the vouchers were valid for only 3 months and were distributed without asking adolescents about their SRHC needs. Many female voucher receivers $(63 \%)$ were not yet sexually active, and thus had limited needs for SRHC services. Among the sexually active girls, $51 \%$ used their voucher, whereas among girls who were not sexually active, voucher use was only $14 \%$.

Focus group discussions and interviews with adolescents during the intervention suggest that the factors that contributed to the success of the voucher program were the removal of practical obstacles (e.g., financial, the need to make an appointment, the lack of information on clinic location, and opening times) plus the guarantee of confidential access to a service provider of their choice. Many of these factors are known to be key features of youthfriendly services ${ }^{[12,15]}$.

It remains to be seen whether the impact will be sustained beyond the voucher program as financial obstacles for confidential care reappear and the financial incentives and guidance given to providers disappear. We hope that the training and experience obtained by the medical staff through the voucher scheme will prompt the provision of services based on the requirements of adolescents and an increase of the number of clinics providing quality SRHC to adolescents. Furthermore, the key finding of this intervention was that accessible health care of good quality can make an important contribution to helping a considerable proportion of girls use SRHC and to diminish the risks of sexual relations, even without their social context being changed.

This is very encouraging because other factors influencing sexual behavior, such as economic deprivation, cultural norms, low educational attainment, and sex inequality are complex issues that will take time to change at a societal level. It might well be that young people reached by the voucher program become the agents for such changes.

A possible reason why other researchers suggest that knowledge and access are not sufficient to change adolescent behavior could be an underestimation of the obstacles faced by adolescents in obtaining contraceptives. Research from other Latin American countries frequently fails to describe and/or investigate local financial and practical barriers to accessing SRHC, and the social and legal acceptability of providing adolescents with contraceptives without parental approval, making the interpretation of low contraceptive use difficult ${ }^{[10,11,16-18]}$. Other intervention studies fall short of showing that obstacles to accessing confidential SRHC have been removed, leaving lack of effective access as an alternative explanation for low contraceptive use ${ }^{[7,8]}$.

Access is crucial for adoption and continued use of modern contraceptives, and it is known that adolescents, especially the youngest, and girls who have not started procreative life, face many obstacles to accessing SRHC in Latin America ${ }^{[3,15,19,20]}$. In our study population, younger girls and girls attending school had the lowest use of SRHC, and showed the strongest increase in use through voucher receipt, as shown in ${ }^{\text {Fig. } 3}$. Vouchers appear capable of removing many of the obstacles these girls face.

Focusing on these groups is likely to increase the overall impact of a program on the use of contraceptives and condoms.

The increased contraceptive use found in this study is compatible with findings from studies in industrialized countries. Although sex education alone does not increase the use of contraceptives and/or prevent unintended pregnancies ${ }^{[21]}$, several studies have documented an increased use of contraceptives when their provision was included in the program ${ }^{[22-25]}$. This is supported by evidence from The Netherlands and other European countries where lowbarrier family planning services for adolescents of all ages have been fundamental in decreasing unwanted teenage pregnancy and abortion ${ }^{[20,26,27]}$.

To conclude, this study emphasizes the diversity among adolescents and the need to classify adolescents correctly to be able to identify specific needs and measure program 
Meuwissen, L.E., Gorter, A.C., Knottnerus, A.J.A. Impact of accessible sexual and reproductive health care on poor and underserved adolescents in Managua, Nicaragua: a quasi-experimental intervention study. Journal of Adolescent Health: 2006, 38(1), 56

impact. The voucher program was capable of meeting the unmet needs of SRHC for many adolescent girls, and was especially successful in reaching out to younger girls, to girls attending school, and to those girls with lower levels of educational attainment. Their needs could be met with a relatively simple intervention, using existing health facilities, and despite a conservative political climate.

The increased use of condoms and contraceptives in specific groups suggests many girls are motivated to protect themselves against the risks of sexual intercourse, once given access to reliable information and confidential health services. This finding underscores the crucial importance of accessible and affordable SRHC, not only for responding to the needs and rights of adolescents, but also for meeting public health objectives.

\section{ACKNOWLEDGMENTS}

The authors thank all the adolescents who shared their views and experiences with us and therefore made this program and the evaluation possible. Without the hard and enthusiastic work of Zoyla Segura, Joel Medina, Patricia Gonzalez, Amelia Tijerino, Roger Torrentes, Alejandro Dormes, Gloria Medina, and Esteban Zuñiga, this intervention never could have become a success. The authors are very grateful to Erik van de Giessen and Julienne McKay for their continuing support during the preparation of this report. Last but not least, without financial support of DFID this interesting intervention would never have been possible.

\section{REFERENCES}

[1] Instituto Nacional de Estadística y Censos y Ministerio de Salud.

Demographic Health Survey Nicaragua 2001 (in Spanish), Managua, Nicaragua, Instituto Nacional de Estadística and Censos y Ministerio de Salud. Calverton, MD USA; Macro International/DHS_Program.

2002.

[2] Zelaya E, Marin FM, Garcia J, et al. Gender and social differences in adolescent sexuality and reproduction in Nicaragua. J Adolesc Health 1997;21:39-46.

[3] Pons JE. Contraceptive services for adolescents in Latin America: facts, problems and perspectives. Eur J Contracept Reprod Health Care 1999;4:246 -54.

[4] Berglund S, Liljestrand J, Marin FM, et al. The background of unwanted adolescent pregnancies in Nicaragua. A qualitative approach.

Soc Sci Med 1997;44:1-12.

[5] United Nations Population Fund. ¿Qué más podría hacer sino tener un hijo? Basis socioculturales del embarazo de las adolescentes en Nicaragua.

[What Else Could I Do Than Getting a Child? Sociocultural Basis of Adolescent Pregnancy in Nicaragua.] Managua, Nicaragua: UNFPA, INIM, RLA/94/P15, 1999.

[6] Braddock M, Hernández SJ, Muiruri Y. Un estudio transcultural de acceso de adolecentes a la educación y a servicios de salud reproductiva.

[Transcultural Study of Access of Adolescents to Education and Reproductive Health Services]. Mary Stopes International, Informe final al Banco Mundial, 1995.

[7] Magnani RJ, Gaffikin L, de Aquino EM, et al. Impact of an integrated adolescent reproductive health programme in Brazil. Stud Fam Plann 2001;32:230-43.

[8] Belmonte LR, Gutierrez EZ, Magnani R, et al. Barriers to adolescents use of reproductive health services in three Bolivian cities. FOCUS on Young Adults/Pathfinder International. Available from: www.

pathfind.org/focus.htm, 2000 (Accessed: December 6, 2000).

[9] Diaz M, Simmons R, Diaz J, et al. Expanding contraceptive choice: findings from Brazil. Stud Fam Plann 1999;30:1-16.

[10] Magnani R, Seiber E, Gutierrez EZ, et al. Correlates of early sexual activity and unprotected sex among urban secondary school students in Peru. Stud Fam Plann 2001;32:53- 66. 56.e8 L.E. Meuwissen et al. / Journal of Adolescent Health 38 (2006) 56.e1-56.e9

[11] Lipovsek V, Karim AM, Gutierrez EZ, et al. Correlates of adolescent pregnancy in La Paz, Bolivia: findings from a quantitative-qualitative study. Adolescence 2002;37:335-52. 
Meuwissen, L.E., Gorter, A.C., Knottnerus, A.J.A. Impact of accessible sexual and reproductive health care on poor and underserved adolescents in Managua, Nicaragua: a quasi-experimental intervention study. Journal of Adolescent Health: 2006, 38(1), 56

[12] Speizer IS, Magnani RJ, Colvin CE. The effectiveness of adolescent reproductive health interventions in developing countries: a review of the evidence. J Adolesc Health 2003;33:324-48.

[13] Gorter A. Evidence of effectiveness of competitive voucher schemes on HIV prevention and care for young people. Background paper prepared for the WHO for the 'Global consultation on the health services response to the prevention and care of HIVIAIDS among young people' organized by WHO, UNICEF, UNFPA, UNAIDS, YouthNet. Geneva, Swiss: WHO, 2003.

[14] Alcaldia de Managua. Managua a Shared Future (in Spanish) Plan General de Desarrollo Municipal, Alcaldia de Managua. Managua: Hermanamiento Amsterdam, 2000.

[15] Senderowitz J. Making reproductive health services friendly for young people. FOCUS on Young Adults/Pathfinder International. Available from: http://www.pathfind.org/pf/pubs/focus/IN\%20FOCUS/ MakingYouthfriendly.html (Accessed September 5, 2000)

[16] Pick de Weiss S, Atkin LC, et al. Sex, contraception, and pregnancy among adolescents in Mexico City. Stud Fam Plann 1991;22:74-82.

[17] Martiniuk AL, O'Connor KS, King WD. A cluster randomized trial of a sex education programme in Belize, Central America. Int J Epidemiol 2003;32:131- 6.

[18] Gupta N, da Costa Leite I. Adolescent fertility behavior. Trends and determinants in Northeastern Brazil. Int Fam Plann Perspect 1999; 25:125-30.

[19] Langer A. El embarazo no deseado: impacto sobre la salud y la sociedad en América Latina y el Caribe. [Unwanted pregnancy: impact on health and society in Latin America and the Caribbean].

Rev Panam Salud Publica 2002;11:192-204.

[20] Treffers PE. Tienerzwangerschapppen, een mondiaal probleem.

[Teenage pregnancy, a worldwide problem]. Ned Tijdschr Geneeskd 2003;147:2320 -5.

[21] DiCenso A, Guyatt G, Willan A, et al. Interventions to reduce unintended pregnancies among adolescents: systematic review of randomised controlled trials. BMJ 2002;324:1426.

[22] Kirby C, Waszak C, Ziegler J. Six school-based clinics: their reproductive health services and impact on sexual behavior. Fam Plann Perspect 1991;23:6 -16.

[23] Tiezzi L, Lipshutz J, Wrobleski N, et al. Pregnancy prevention among urban adolescents younger than 15: results of the 'In Your Face' program. Fam Plann Perspect 1997;29:1736, 197.

[24] Lou CH, Wang B, Shen Y, Gao ES. Effects of a community-based sex education and reproductive health service program on contraceptive use of unmarried youths in Shanghai. J Adolesc Health 2004;34: 433-40.

[25] Frost JJ, Forrest JD. Understanding the impact of effective teenage pregnancy prevention programs. Fam Plann Perspect 1995;27:188- 95.

[26] Ketting E, Visser AP. Contraception in The Netherlands: the low abortion rate explained. Patient Educ Couns 1994;3:161-71.

[27] Furstenberg FF. When will teenage childbearing become a problem? The implications of western experience for developing countries. Stud Fam Plann 1998;29:246 -53. 
Meuwissen, L.E., Gorter, A.C., Knottnerus, A.J.A. Impact of accessible sexual and reproductive health care on poor and underserved adolescents in Managua, Nicaragua: a quasi-experimental intervention study. Journal of Adolescent Health: 2006, 38(1), 56

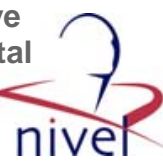

TABLES AND FIGURES

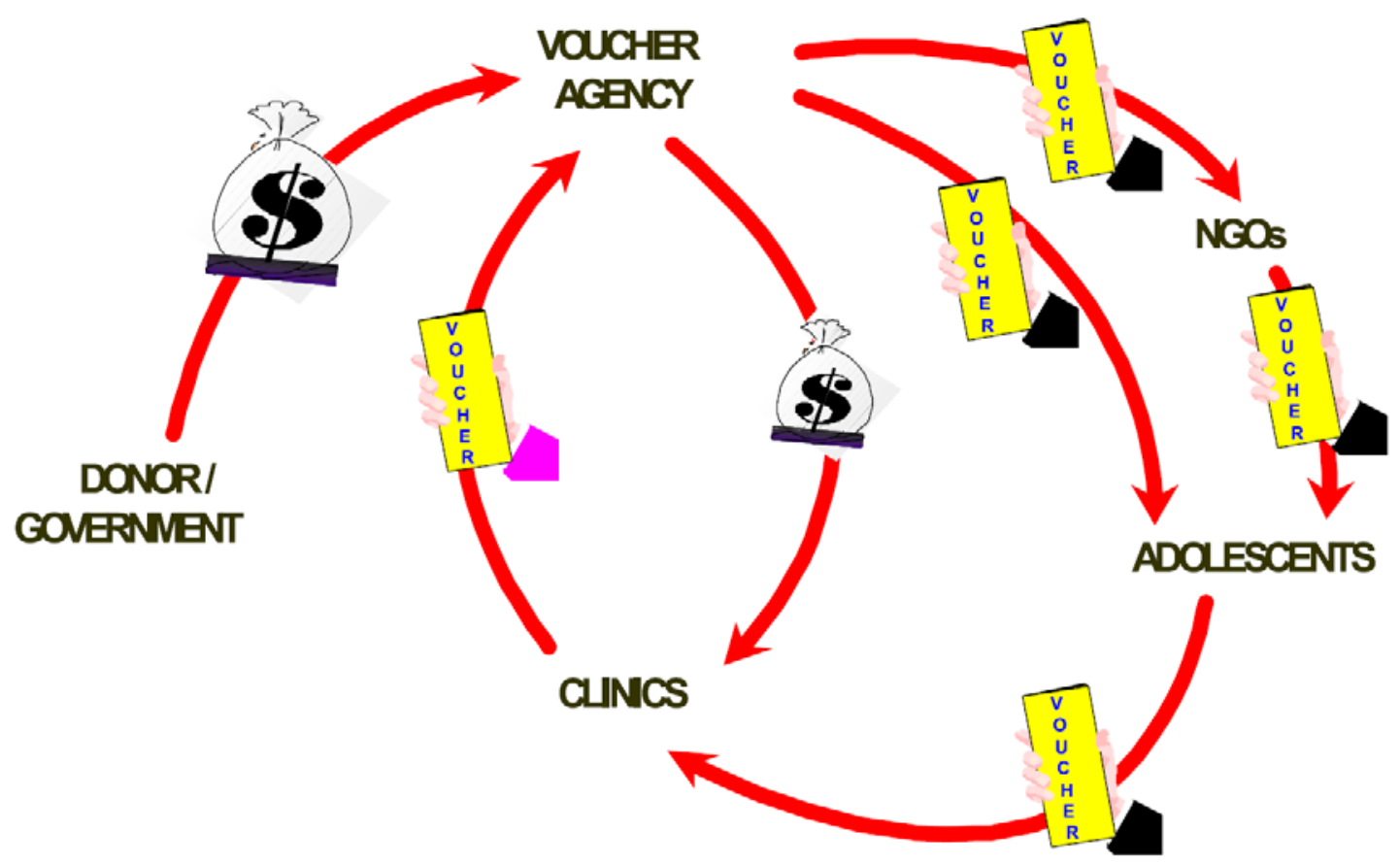

Fig. 1. Schematic presentation of the voucher scheme.

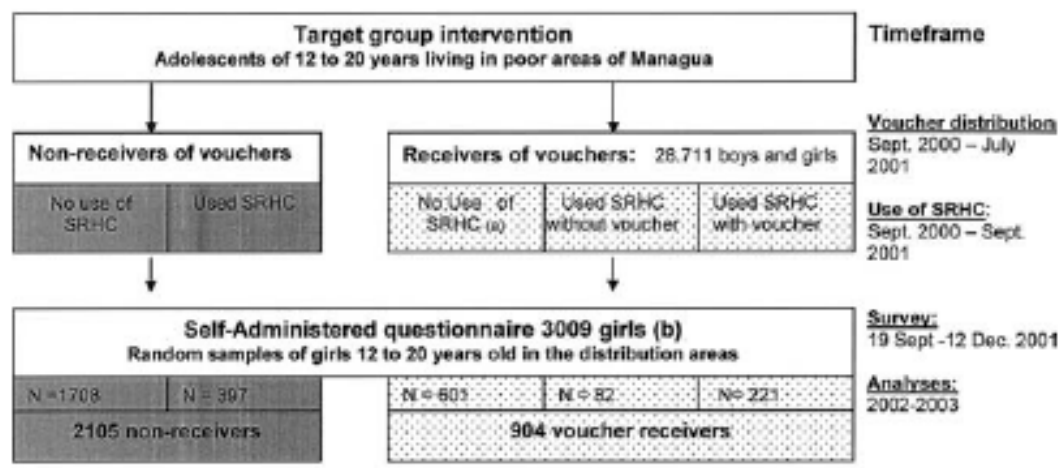

(a) Includes 30 voucher uscrs who visited the heath oenters for other reosons than SRHC

Fig. 2. Flow diagram of the intervention and evaluation of the voucher program. (a) Includes 30 voucher users who visited the health centers for reasons other than SRHC. 
Meuwissen, L.E., Gorter, A.C., Knottnerus, A.J.A. Impact of accessible sexual and reproductive health care on poor and underserved adolescents in Managua, Nicaragua: a quasi-experimental intervention study. Journal of Adolescent Health: 2006, 38(1), 56

Table 1

Characteristics of voucher receivers and nonvoucher receivers during the survey

\begin{tabular}{|c|c|c|c|c|}
\hline Total & & $\begin{array}{l}\text { Nonreceivers } \\
\mathrm{N}=2105(\%)\end{array}$ & $\begin{array}{l}\text { Receivers } \\
\mathrm{N}=904(\%)\end{array}$ & $p$ \\
\hline \multirow[t]{3}{*}{ Age group } & $12-15 \mathrm{y}$ & $721(34.3)$ & $230(25.4)$ & \\
\hline & $16-17 y$ & $558(26.5)$ & $286(31.6)$ & \\
\hline & $18-21$ y & $826(39.2)$ & $388(42.9)$ & $<.01$ \\
\hline \multirow[t]{4}{*}{ Education (missing $=5$ ) } & $0-6 y$ & $389(18.5)$ & $123(13.7)$ & \\
\hline & $7-9 y$ & $987(46.9)$ & $381(42.3)$ & \\
\hline & $10-11$ y & $528(25.1)$ & $207(23.0)$ & \\
\hline & $12-16 y$ & $199(9.5)$ & $190(21.1)$ & $<.01$ \\
\hline \multirow[t]{2}{*}{ Attending school (missing $=5$ ) } & No & $663(31.5)$ & $212(23.5)$ & \\
\hline & Yes & $1,440(68.5)$ & $689(76.5)$ & $<.01$ \\
\hline \multirow[t]{2}{*}{ Refrigerator $($ missing $=19$ ) } & No & $1,045(50.0)$ & $443(49.1)$ & \\
\hline & Yes & $1,043(50.0)$ & $459(50.9)$ & .64 \\
\hline \multirow[t]{3}{*}{$\mathrm{Nb}$ people/bedroom (missing $=50$ ) } & $0-2$ & $1,013(49.0)$ & $451(50.7)$ & \\
\hline & More than 2-3 & $579(28.0)$ & $263(29.6)$ & \\
\hline & More than 3 & $477(23.1)$ & $176(19.8)$ & .14 \\
\hline \multirow[t]{3}{*}{ SE classification by survey site } & Lower/lower middle & $535(25.4)$ & $366(40.5)$ & \\
\hline & Poor & $1041(49.5)$ & $359(39.7)$ & \\
\hline & Very poor & $529(25.1)$ & $179(19.8)$ & $<.01$ \\
\hline \multirow{3}{*}{ Place questionnaire } & Market & $507(24.1)$ & $184(20.4)$ & \\
\hline & Neighborhood & $961(45.7)$ & $319(35.3)$ & \\
\hline & Outside school & $637(30.3)$ & $401(44.4)$ & $<.01$ \\
\hline \multirow[t]{3}{*}{ Sexually active (missing $=55^{*}$ ) } & Not started & $1,366(66.1)$ & $563(63.4)$ & \\
\hline & Started, not a mother & $301(14.6)$ & $172(19.4)$ & \\
\hline & Mother and/or pregnant & $399(19.3)$ & $153(17.2)$ & 0.01 \\
\hline
\end{tabular}

Note: $\mathrm{N}=3009$.

* 29 girls who did not complete the second page of the questionnaire, where they were asked about sexual relations, pregnancy, and children, and 26 with missing data regarding the specific question.

Table 2

Differences in characteristics between voucher receivers and nonreceivers per survey site

\begin{tabular}{|c|c|c|c|c|c|c|c|c|c|c|}
\hline Survey sites & $\begin{array}{l}\text { Voucher } \\
\text { receipt }\end{array}$ & Number $(\%)$ & \%oucher use* & Mean age & $\begin{array}{l}\text { Years of } \\
\text { school, } \\
\text { mean }\end{array}$ & $\begin{array}{l}\text { Percent presently } \\
\text { at school }\end{array}$ & $\begin{array}{l}\text { No } \\
\text { refrigerator }\end{array}$ & $\begin{array}{l}\text { People per } \\
\text { bedroom }\end{array}$ & $\begin{array}{l}\text { SE } \\
\text { score }\end{array}$ & Started $^{\dagger}$ \\
\hline \multirow{2}{*}{$\begin{array}{l}\text { Markets } \\
\qquad(\mathrm{N}=691)\end{array}$} & Yes & $184(27)$ & \multirow{2}{*}{28.3} & 17.5 & 8.7 & 61 & 54 & 2.4 & 1.6 & 49 \\
\hline & No & $507(73)$ & & 17.6 & 8.6 & $49^{\ddagger}$ & 49 & 2.4 & 1.7 & 54 \\
\hline \multirow{2}{*}{$\begin{array}{l}\text { Neighborhoods } \\
(\mathrm{N}=1,280)\end{array}$} & Yes & $319(25)$ & \multirow[t]{2}{*}{35.7} & 16.5 & 7.5 & 58 & 61 & 3.0 & 1.1 & 43 \\
\hline & No & $961(75)$ & & 16.3 & 7.5 & 63 & 58 & 2.9 & 1.0 & $35^{+}$ \\
\hline \multirow{2}{*}{$\begin{array}{l}\text { At schools } \\
\qquad(\mathrm{N}=1,038)\end{array}$} & Yes & $401(39)$ & \multirow[t]{2}{*}{21.5} & 17.1 & 10.3 & 98 & 38 & 2.3 & .2 & 26 \\
\hline & No & $637(61)$ & & $16.3^{\frac{8}{8}}$ & $9.3^{8}$ & $93^{8}$ & 39 & 2.4 & $4^{8}$ & $15^{\frac{8}{8}}$ \\
\hline \multirow{2}{*}{$\begin{array}{l}\text { All } \\
\qquad(\mathrm{N}=3,009)\end{array}$} & Yes & $904(30)$ & \multirow[t]{2}{*}{27.9} & 17.0 & 9 & 76 & 49 & 2.6 & .8 & 37 \\
\hline & No & $2,105(70)$ & & $16.6^{\frac{8}{8}}$ & $8.3^{8}$ & $68^{8}$ & 50 & 2.6 & $1.0^{8}$ & $34^{\frac{8}{8}}$ \\
\hline
\end{tabular}

Significance of difference between receivers and nonreceivers:

* Percent of receivers who used voucher.

${ }^{\dagger}$ Percent who initiated sexual intercourse.

$\neq .05<p<.01$.

${ }^{8} p<.01$. 
Table 3

Multiple logistic regression models: the impact of the reception of vouchers on the use of SRHC, knowledge of FP and STIs, and the use of family planning and contraceptives

\begin{tabular}{|c|c|c|c|c|c|c|c|c|c|}
\hline \multicolumn{2}{|l|}{$\%$ Outcome } & \multirow[b]{2}{*}{$\begin{array}{l}\text { Total* } \\
\mathrm{N}=3009\end{array}$} & \multirow{2}{*}{$\begin{array}{l}\text { Entire group }^{\dagger} \\
\text { Adjusted odds ratio } \\
\text { (95\% confidence } \\
\text { interval) }\end{array}$} & \multirow[b]{2}{*}{$\mathrm{N}$} & \multirow{2}{*}{$\begin{array}{l}\text { Markets }^{\dagger} \\
\text { Adjusted odds ratio } \\
(95 \% \text { confidence } \\
\text { interval) }\end{array}$} & \multirow[b]{2}{*}{$\mathrm{N}$} & \multirow{2}{*}{$\begin{array}{l}\text { Neighborhoods }^{\dagger} \\
\text { Adjusted odds ratio } \\
\text { (95\% confidence } \\
\text { interval) }\end{array}$} & \multirow[b]{2}{*}{$\mathrm{N}$} & \multirow{2}{*}{$\begin{array}{l}\text { At schools }^{\dagger} \\
\text { Adjusted odds ratio } \\
(95 \% \text { confidence } \\
\text { interval) }\end{array}$} \\
\hline Nonreceivers & Receivers & & & & & & & & \\
\hline 19 & 34 & 2,899 & 3.07 (a) $(2.45-3.84)$ & 681 & 2.54 (b) $(1.66-3.90)$ & 1,232 & 2.98 (b) $(2.11-4.20)$ & 1,005 & 5.92 (c) $(3.67-9.54)$ \\
\hline 65 & 74 & 2,949 & 1.29 (d) $(1.07-1.55)$ & 686 & .98 (e) $(.67-1.44)$ & 1,258 & 1.30 (e) $(.97-1.73)$ & 1,005 & 1.56 (f) $(1.14-2.14)$ \\
\hline 43 & 51 & 2,949 & 1.32 (d) (1.11-1.57) & 686 & .97 (e) $(.68-1.40)$ & 1,258 & $1.52(\mathrm{~g})(1.15-2.02)$ & 1,005 & 1.46 (h) $(1.11-1.94)$ \\
\hline 50 & 50 & $853^{\ddagger}$ & 1.33 (i) $(.77-2.29)$ & 307 & 1.19 (c) (.69-2.04) & 379 & .75 (j) $(.47-1.20)$ & 174 & $2.27(\mathrm{k})(1.18-4.36)$ \\
\hline 37 & 49 & 2,949 & 2.56 (1) (1.59-4.10) & 686 & $.97(\mathrm{~m})(.66-1.44)$ & 1,258 & 2.65 (n) $(1.55-4.53)$ & 1,036 & 1.57 (o) $(1.20-2.07)$ \\
\hline 47 & 54 & 2,949 & 1.21 (p) $(1.03-1.43)$ & 686 & 1.29 (f) $(.90-1.84)$ & 1,258 & 1.48 (e) (1.14-1.92) & 1,007 & $1.03(\mathrm{k})(.79-1.33)$ \\
\hline 20 & 23 & $835^{ \pm}$ & 1.84 (q) (1.11-3.03) & 301 & $.60(\mathrm{r})(.27-1.29)$ & 373 & $2.47(\mathrm{~s})(1.35-4.54)$ & 165 & $1.67(\mathrm{t})(.79-3.53)$ \\
\hline
\end{tabular}

Knowledge prevention

Note: Adjus tments could be made for the following variables: (I) category of childbearing: (II) survey site; (III) level of education; (IV) attending school; (V) age group; (VI) SE score area; (VII) number of people per bedroom; (VIII) interaction reception; place interview; (IX) interaction reception education; (X) Interaction reception attending school. Adjustment was made for: (a) I, II, VI, VII; (b) I, VI, VII; (c) I, IV; (d) I, II, III, V; (e) I, III, V; (f) I, III; (g) I, III, V, VI; (h) I, III, IV, V; (i) I, II, VII, VIII; (j) I, VII; (k) I; (l) I, II, III, IV, VI, IX; (m) I, III, VI; (n) I, III, IV, IX; (o) III, IV, V, VI; (p) I, II, III; (q) II, IV, VII, X; (r) IV; (s) IV, VII, X; (t) III, VII

* Number of records used for each logistic regression model. Each model includes only those variables significant for that outcome at that site. Therefore, the number of records used varies and does not necessarily add up to the total for that outcome. $\mathrm{N}=3009$, distributed over the different locations as follows: markets 691 , neigborhoods 1,038 , and schools 1,038 . For sexually active see

${ }^{\dagger}$ Adjusted for all significant variables, indicated with letters between brackets.

${ }^{*}$ Based on 888 girls who are sexually active, not pregnant, and do not want a baby in the coming year. $\mathrm{N}=888$ : markets, 311 ; neighborhoods, 395 ; and schools, 182. 
Meuwissen, L.E., Gorter, A.C., Knottnerus, A.J.A. Impact of accessible sexual and reproductive health care on poor and underserved adolescents in Managua, Nicaragua: a quasi-experimental intervention study. Journal of Adolescent Health: 2006, 38(1), 56

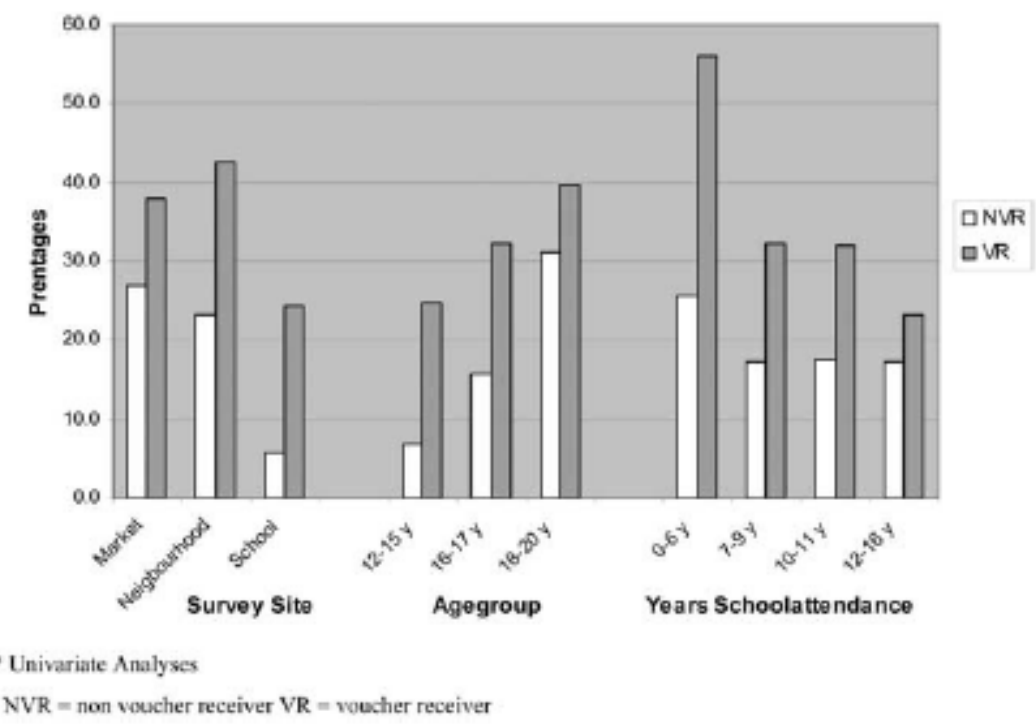

Fig. 3. Impact of vouchers on use of SRHC by subgroups. *Univariate analyses. NVR, nonvoucher receiver; VR, voucher receiver. 